Volume 2

Number 2 Popular Culture and Markets in

Turkey

\title{
NGOs in Turkey's Media Field: Causes, Sources and Potentials for Development
}

\author{
Altug Akin \\ Izmir University of Economics \\ Burak Dogu \\ Izmir University of Economics
}

Follow this and additional works at: https://digitalcommons.uri.edu/mgdr

Part of the Civic and Community Engagement Commons, Communication Technology and New Media Commons, Journalism Studies Commons, and the Nonprofit Administration and Management Commons

\section{Recommended Citation}

Akin, Altug and Dogu, Burak (2017) "NGOs in Turkey's Media Field: Causes, Sources and Potentials for Development," Markets, Globalization \& Development Review. Vol. 2: No. 2, Article 5.

DOI: 10.23860/MGDR-2017-02-02-05

Available at: https://digitalcommons.uri.edu/mgdr/vol2/iss2/5

This Article is brought to you for free and open access by DigitalCommons@URI. It has been accepted for inclusion in Markets, Globalization \& Development Review by an authorized editor of DigitalCommons@URI. For more information, please contact digitalcommons-group@uri.edu. 
NGOs in Turkey's Media Field: Causes, Sources and Potentials for Development

\section{Markets, Globalization \& Development Review}
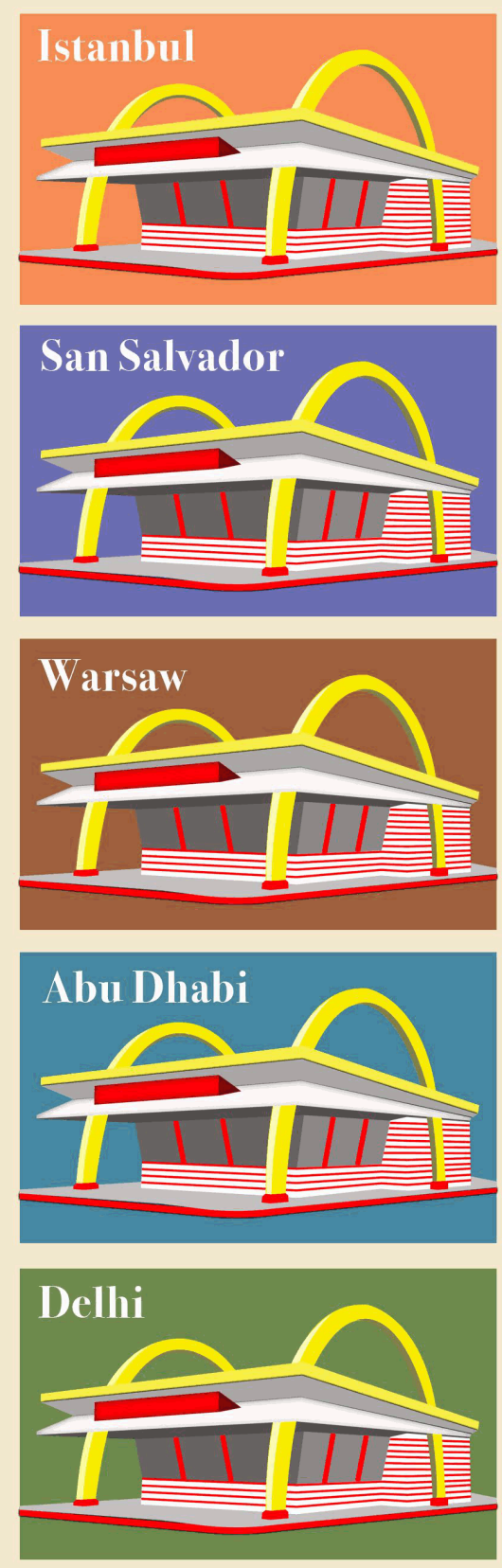
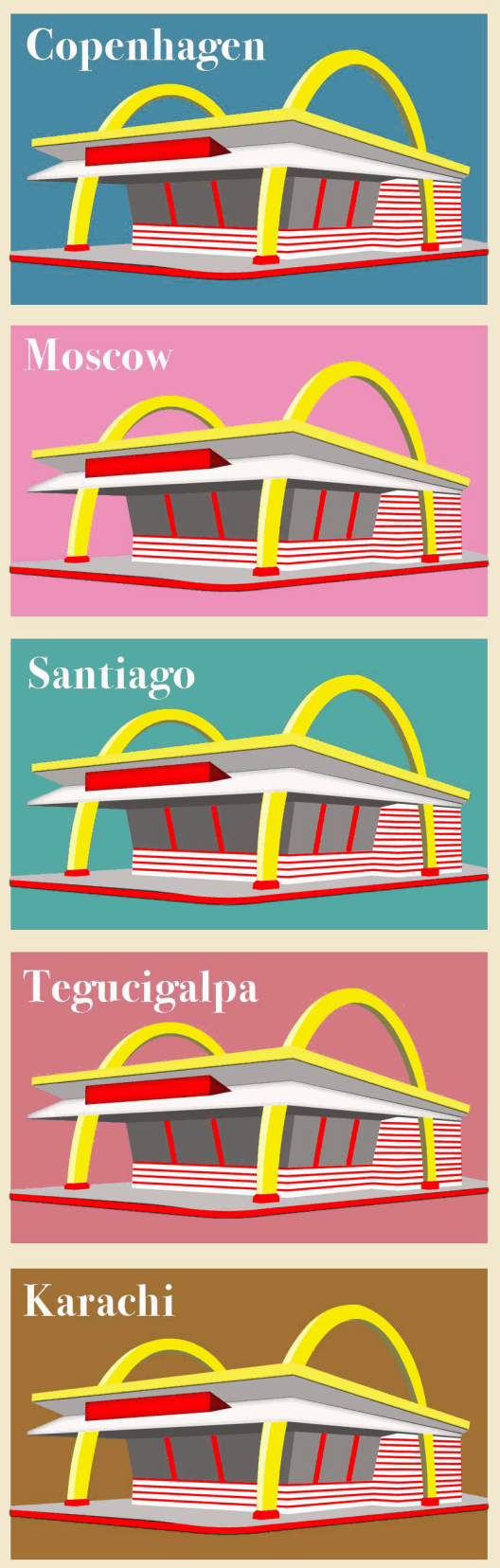
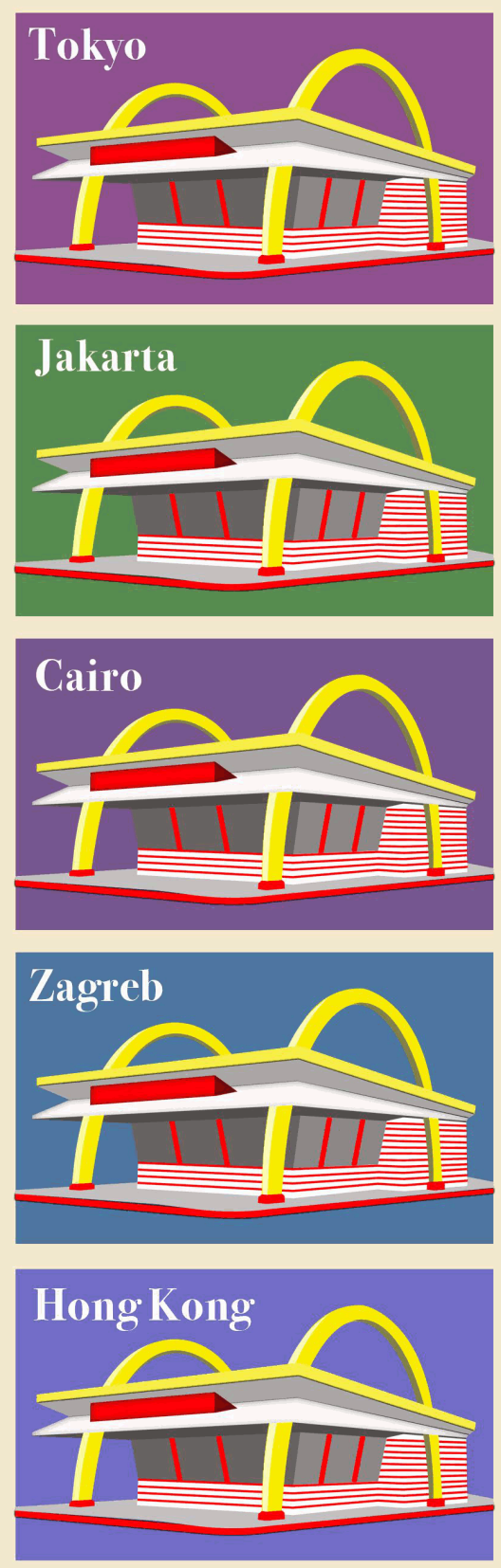

This article is available in Markets, Globalization \& Development Review: https://digitalcommons.uri.edu/mgdr/vol2/ 


\section{NGOs in Turkey's Media Field: Causes, Sources and Potentials for Development}

\section{Introduction}

Turkey has an affluent media landscape where a vast number of conventional print and broadcast media institutions, along with alternative organizations, sustain their subdomains with relation to their interests, policies and ideologies. These institutions have continued their activities over the past decades in a very dynamic field that has been subject to concentration, polarization and pressure. Therefore, their operations are influenced by many factors considering the wider composition of social forces in the political environment. Currently, media in Turkey are exposed to challenges of different kinds at multiple levels. As a democratizing force, civil society is a potential buffer for these challenges. Indeed, there is a plethora of non-governmental organizations (NGOs) in Turkey, operating in the broadly defined field of media. These range from professional employee associations, such as the Turkish Journalists' Association, media-monitoring organizations such as the Hrant Dink Foundation; and from academic associations such as the Communication Research Association, to think-tanks such as the Journalists and Authors' Foundation. There are a large number of organizations, movements and platforms whose activities are directly related to diverse aspects of the field of media.

Most are concerned with resolving current problems in their relevant subdomain of the media market, and act in accordance with goals for development or enrichment (Fenton 2010). This paper examines the role of such NGOs operating in the media field, focusing on two of the most disputed sectors of the media in Turkey: news and information technologies (IT). These are vital components of the broader media field in the country, first due to the direct political pressure they experience, and second, because of the structural deficiencies they display. According to those within the field as well as independent observers, these areas are in urgent need of substantial transformation (Aktar 2005; Altıparmak and Akdeniz 2008; Binark 2012; Binark and Löker 2011; Dağıstanlı 2014; Özsever 2004). We will study how NGOs in these subdomains are improving the conditions to which media producers and society are exposed. Below, we present our approach to civil society and draw the framework for the operational context of NGOs. 


\section{An Intrinsic Approach to Civil Society}

The origin of the terms civil society and civil society organization (or nongovernmental organization - NGO) have been highly debated and contested and the terms have been open to diverse interpretations (Cohen and Arato 1992; Edwards 2004; Setianto 2007; Wiarda 2003). In this study, due to its practical advantages and its long term use, the Civicus Civil Society Index's (CSI) minimal yet operational definition of civil society is employed: "The arena, outside of the family, the state, and the market where people associate to advance common interests" (Bikmen and Meydanoğlu 2006). In the context of this study, we defined the NGOs that were researched as voluntary organizations that aim to produce solutions and operate autonomously from the state. In line with this definition, we conceptualize the notion of market as a social space governed by the competing values of social and economic norms, therefore having a potential for the enrichment of cooperative and collaborative social practice (Dholakia and Atik 2016). This approach is appropriate for conceptualization, where both civil society and organizations are viewed in terms of their impact, and on the basis of their contribution to solving problems pertaining to the field of media. We also frame civil society within this perspective to examine the dynamics between markets and development in Turkey, a country where the fundamentals of democracy are contested. Yet, we acknowledge the limitations or shortcomings of such a conceptualization of civil society, which we briefly discuss in the conclusions.

Civil society in Turkey has been a major concern not only in academia, but also among policy makers in recent decades (Kuzmanovic 2010) where a number of issues have been brought into focus. Concerns include the growth of civil society and its potential role in the democratization process, power inequalities, socio-political reforms (particularly regarding the rapprochement between Turkey and the European Union), and challenging the norms of conventional politics. Civil society organizations are acting as mediators between the private sector and the state, which is also an area of concern. In contrast, the qualities of specific domains such as the media have not been investigated in detail. Civil society is generally understood as a single, homogenous concept, and therefore, there has been a lack of attention to the qualities of different groups within a plurality of civil societies (Şimşek 2004). For instance, civil society organizations operating in the media field deal with multiple media-related issues and have complicated forms and functions. These include self-regulation, monitoring, deliberation, networking, sponsorship, and advocacy. It is important to understand the internal 
dynamics of civil society organizations in order to reveal their contribution to transformations in their field as it relates to the existing power structures.

There have also been several attempts at measuring and assessing the health of civil society through diverse approaches and methods, some focusing on the volume and capacity of organizations in a particular environment, others more concerned with membership structures (Fioramonti and Kononykhina 2015). Recently, the CSI marked a milestone for allowing dynamic analysis of civil society's internal differences based on the function of organizations rather than their formal legal status or mission (Fioramonti and Kononykhina 2015). The participatory action-research project developed by the CSI assessed the state of civil society in a comparative manner, involving more than 50 countries from around the world, including Turkey. The project linked this assessment with a reflection and action-planning process by civil society stakeholders, aiming to strengthen civil society in those areas where weaknesses or challenges are detected (İçduygu, Meydanoğlu and Sert 2011). Following up on this framework drawn by the CSI, we expand into the internal dynamics of civil society organizations-in the field of news and IT by conducting qualitative analysis of primary data collected through indepth interviews with organizational representatives.

Recent literature on civil society emphasizes two distinct approaches in regards to external structural constituents and internal characteristics of organizations. At the structural level, people's perceptions of civil society have been questioned on the grounds that both its autonomy and the capacity are constrained politically and economically (Paker et al. 2013). The internal level, on the other hand, suggests a plurality of civil societies, with actors that may have different features and objectives, including contrasting internal dynamics (Fioramonti and Kononykhina 2015). With these two perspectives in mind, we present an intrinsic approach to civil society and reflect on NGOs operations, financial and organizational forms, as well as relations with different actors considering their reflexive practices contributing to the improvement of their subdomains.

Our aim is to analyze the efforts of the news and IT based subdomains of these NGOs to reveal their modus operandi in dealing with issues of their concern. We analyze the findings in relation to existing problems of the media industry in Turkey (media concentration, censorship, bias etc.) and explore the following questions:

- What is the primary purpose of the media related, i.e. the news and IT NGOs, in Turkey? 
- How do they operate?

- With whom do they ally or conflict?

Methodologically, this study consults primary sources, namely the representatives of the selected eight NGOs, four of each from the news and IT subfields. In-depth interviews with the representatives were conducted. Organizations for the case study were selected among the NGOs that have, throughout their history, discursively and practically presented their concerns, to improve their subdomains in line with the democratic principles. First, a set of open-ended questions was used to collect data from within the organizations. Secondly, existing studies on the relevant media subdomains in Turkey were reviewed, and other NGOspecific materials analyzed, including the information obtained from the organizations' websites along with their publications and projects. This data was analyzed to shed light on the current state of the media subdomains, and to observe each NGOs' contributions to the enrichment of the field of media in Turkey. Here, the purpose is to propose recommendations (to the NGOs) for improving the conditions of the market.

Accordingly, the first section of this article provides an outline of the media industry in Turkey and a contextualization of media-related NGOs, particularly those operating in the news and IT subdomains. This is followed by a presentation of their goals, organizational characteristics and relations. The following section addresses the questions "Why do they exist?", "How do they operate?" and "With whom do they ally or conflict?" Finally, in the conclusion, our findings are briefly discussed within the context of civil society in Turkey.

\section{Operational Context of NGOs: Turkey's Media Landscape}

NGOs subject to this research operate in a sophisticated media landscape in Turkey. Hundreds of television channels, thousands of local and national radio stations, several dozen newspapers, a productive and profitable national cinema and a rapid growth of broadband Internet use all make up a very vibrant media industry in Turkey (Tuncel 2011). According to TÜIK (2015) data, the total number of newspapers currently circulating in Turkey is 2,731. 172 of these are national, 112 regional and 2,447 local. The print media is distributed by the owners of large conglomerates. Aside from print media there are 43 national, 79 regional, 803 local television channels and 265 satellite, cable, and Internet broadcasting stations, including the public broadcaster Turkish Radio and Television Corporation (TRT). Since 2002, the potency of the governing Justice and Development Party (Adalet Kalkınma Partisi - AKP) has lead the TRT to take a rather 
partisan position (Yesilada and Rubin 2012). After losing its monopoly on broadcasting in the early 1990s TRT has recovered its position. Now, TRT has 13 television channels and 16 radio stations along with its website (www.trt.net.tr). Currently, the number of private radio channels in Turkey is around 734, among which 13 are national, 58 are regional and 663 are local. Frequency distribution continues to be an unresolved problem, since all terrestrial broadcasting stations are able to operate without licenses.

Since the 1990s, ownership in this affluent media market has been concentrated in a small number of large capital groups that operate in various markets including media investment. Media groups such as Doğan, Ciner, Çukurova, Doğuş, and Feza are owned by stakeholders who invest widely, but primarily in the banking, energy, automotive, and building sectors. Media organizations such as these tend to develop close relations with the state. Political influence on the media has been increasingly observed over the last decade, as the AKP government has a deliberate agenda for changing the media landscape. For example excessive taxation was imposed on media companies opposing governmental actions. Additionally, several television stations were removed from the satellite broadcast providers, such as Digiturk, Tivibu, and Teledünya immediately before the general elections in November 2015, and again after the failed coup attempt in summer of 2016. The strategy of acquiring and selling bankrupt media firms to pro-government capital owners has become government policy, resulting in sharp polarization of media organizations. This strategy has lead to the emergence of new actors, such as the Turkuvaz Group, closely aligned with the government. The media now represents a divided and highly political field, where corporations are increasingly polarized (Kurban and Sözeri 2012).

Broadcasting activities in Turkey are regulated by the Radio Television Supreme Council (RTÜK). Established after the termination of the state monopoly on broadcasting in 1994, RTÜK's primary mandate is to regulate private broadcasting and to ensure compliance with the law. RTÜK was made responsible for assigning frequencies and issuing broadcasting permits and licenses to private companies. It has the authority to penalize broadcasters for breaking the law; penalties range from warnings to suspension of television and radio stations (Barış n.d). Since its foundation, RTÜK has been subject to government pressures and currently serves as the apparatus for imposing penalties. After the failed coup attempt in July 2016, several television channels' broadcasting licenses were revoked, numerous publications were closed and more than a hundred journalists were imprisoned, sometimes for reasons unrelated 
to the coup attempt, based merely on opposition to government policy (Akin 2016). Thus, Turkey has fallen to $151^{\text {st }}$ out of 180 countries in Reporters without Borders' Press Freedom Index (2016).

The Internet is another platform on which direct and indirect pressures are observed. More than 100.000 websites have been banned by the Presidency of Telecommunication (TiB), an organization that, before its closure in 2016, dealt officially with the regulation of Internet content (Engelli Web 2015). Some social networking sites such as Twitter and Facebook along with the video-sharing website Youtube have also been periodically shut down. During certain cases, such as a disturbance in 2013 the bandwidths allocated to the aforementioned websites were decreased. The Internet Bill 5651, widely considered to be the baseline for censorship, also authorized the TiB's autonomous position. Accordingly, Turkey is among the top countries requesting information from Twitter (Twitter Transparency Report 2016). In this whole picture, many users of the Internet turn to VPN clients or tend to change their DNS numbers.

\section{Media-related NGOs in Turkey}

Within this vast media landscape in Turkey, media-related NGOs constitute a significant portion of the civil society. These are neither typical media production institutions nor are they established outside of the state agencies. Dozens of organizations operate in the wide ranging media market, some at national level, others at the local level. Among these, there are professional associations, business organizations, trade unions, self-regulation structures, as well as other NGOs whose activities include work in the field of media. These NGOs set their priorities based on the problems they face in defining the media environment in Turkey, and design their objectives, functions and structures accordingly.

The NGOs studied in this research are from two subdomains of the media field, news and IT. The four from the news field are Izmir Journalists Association, Photojournalists Association of Turkey, IPS Communication Foundation, and Journalists Union of Turkey. Izmir Journalists Association (IGC) was founded in 1946 along with counterparts in Istanbul and Ankara. When the Istanbul Journalists Association transformed into Turkish Journalists' Association, other journalists' associations in Anatolia merged to form the Federation of Journalists of Turkey (TGF). Currently, TGF represents all the journalists' associations in Turkey except the one in Istanbul. IGC currently has 830 members, each of whom is automatically enrolled in the TGF. Photojournalists Association of Turkey (TFMD) was founded in 1984 and currently has 565 members nationwide. The association is based in Ankara, with regional representatives across the country. IPS 
Communication Foundation was established in 1993 with the aim of "realizing and supporting projects in the area of communication and development." Their primary contribution is the Bianet, which serves as one of the most significant alternative media in Turkey. Founded in 1952, the Journalists Union of Istanbul changed its name to Journalists Union of Turkey (TGS) in 1963, in an effort to attain status as a national organization.

Four NGOs belonging to the IT field are Alternative Informatics Association, Turkish Linux Users Association, Pirate Party of Turkey, and Internet Technologies Association. Alternative Informatics Association (ABD) was founded in 2010 to address such issues as digital rights, surveillance policies, and Internet censorship, and draws its membership from both the IT sector and the academic community. Since its foundation, $A B D$ has been one of the most active organizations in the field. The Turkish Linux Users Association's (LKD) roots emerged in the early 1990's, when the first organizational efforts started with a mailing list, but the association was not officially founded until 2000 . They aim to spread the use of Linux; however, their priority is on free software activism. The Pirate Party of Turkey (KP) is a subsidiary of the Swedish Pirate Party. Their interests include issues such as copyright, data protection, Internet censorship, and surveillance. In Turkey the KP is a loosely-defined organization, unlike their counterpart in Sweden that is organized as a political party. The UNIX Users Association was established in 1989 and later emerged as the Internet Technologies Association (INETD), mainly involved in organizing conferences and workshops.

Having introduced the broader media landscape in Turkey and the news-related and IT-related NGOs studied in this research, the findings from the research are presented and discussed in the remainder of the paper.

\section{Goals and Actions}

The goals of NGOs operating in the fields of news and IT, it can be generalized, are to create platforms around which their members or volunteers can unify, cooperate and potentially mobilize in order to advance their various interests. For example, TFMD unites primarily a sub-group of Turkish journalists, namely, photojournalists and by doing so the association aims to fulfill three functions. First, they seek to promote their work and labor in order to add value to the profession. Second, they create various benefits for members and third, they apply public pressure on the relevant authorities to take action in regards to the issues concerning their members. In a similar vein, IGC primarily aims to 
reinforce solidarity among its members, and to promote journalism, fighting for press freedoms and emphasizing the rights of media workers. It is important to point out that both TFMD and IGC are "professional associations" which require members' employment in that specific profession or sector, photojournalism and journalism respectively.

There are other NGOs in the media field that are "civil society organizations" rather than "professional associations". These are nonprofit organizations working chiefly for the benefit of the public rather than the individual members. ABD, for instance, works for the public good, rather than interests of their "members" who are more akin to volunteers rather than fee paying members of a specific sector: "Most of the associations in Turkey look after their own benefits. We have established the ABD with the aim of rights and freedom advocacy" (Ali Rıza Keleş, personal communication, June 17, 2014). Their work is organized around possible benefits to society, for instance disseminating information on ITrelated issues such as censorship, citizens' rights, surveillance, legal support, and potential uses of new media. Similarly, IPS Foundation, operating in the news field, is concerned with different forms of "production" (news, reports, publications etc.) as alternatives to mainstream news, rather than focusing on enhancing members' conditions and interests.

In the other NGOs studied, the weight of internal (members) and external (societal) goals is virtually balanced: INETD, for instance, functions as a platform for promoting agendas that benefit society in general, such as the spread of open source programming culture in Turkey. However, in order to reach this goal, it aims to maximize its membership base by providing various ways for sharing common interests in open source culture. A similar balance of internal and external goals is sought in IT-related NGOs studied in this research, namely LKD and KP. The latter, that has the eventual aim of transforming into a political party, focuses on larger social aims. In other words, the internal aims generally serve as an initial step, or a prerequisite for addressing broader goals related to societal problems: NGOs need to survive by serving their own members' needs in order to produce a transformative effect on their relevant fields.

Another dimension of how NGOs define their goals is related to changes in their broader operational context, namely the field of Turkish media in general, and the fields of news and IT in particular. NGOs' priorities tend to change in parallel with the transformations in the sociopolitical agenda, in so far as these reflect on their operational fields. For example, the priority of the $\mathrm{KP}$, in line with its international counterparts 
(David and Halbert 2014), was originally related to copyright issues or promotion of open source forms of collective ownership. However, they are obliged to take action on issues of Internet censorship and data security at times when such issues dominate Turkey's agenda. Other examples of defining or transforming goals and priorities in relation to changing socio-political developments can be seen in the efforts of the TGS in pursuing the case of imprisoned journalists, and, demonstrating solidarity, by visiting news organizations experiencing various forms of political pressure.

In relation with the above-stated goals, news-related and IT-related NGOs in Turkey perform a range of actions, which are the major methods for sustaining their existence. A study of the actions of the NGOs that are "professional organizations", such as TFMD and IGC, target both members and society, but those targeting the former are dominant. IGC, for instance, provides scholarships to its members, and many NGOs organize competitions and exhibitions. These types of competitions or exhibitions hosted by TFMD aim to promote the members' works by providing a public spotlight. This approach has two purposes: Motivating the photojournalists (by promoting their works), and raising public awareness about the importance of photojournalism (Kadir Kemaloğlu, personal communication, June 17, 2014). The latter indirectly targets employers, who are deemed as crucial actors for the survival of photojournalists in a fiercely competitive working environment. Unsurprisingly, the journalist union TGS organizes collective actions targeting employers. As stated by the head of TGS İstanbul, "they collectively demand securing their rights in a shrinking economic sector" (Gökhan Durmuş, personal communication, August 29, 2014).

For most media-related NGOs, providing benefits to their members and forming public pressure in regards to the issues concerning those members are closely linked. The former is generally a tangible benefit. On the micro level, a discounted deal with a supplier for the members; on the macro level, campaigning for legislative change to improve members' social security conditions. Creating public pressure can take the form of organizing campaigns to raise public awareness about issues that have a negative impact on their members. For instance, in 2014 TFMD organized numerous simultaneous press declarations in major Turkish cities about the kidnapping of Bünyamin Gezer, a member photojournalist covering the crisis in Syria, calling on the foreign ministry to implement urgent diplomatic action. According to one TFMD board member, these public actions increased the pressure on the government, resulting in his release (Kadir Kemaloğlu, personal communication, June 17, 2014). Similarly, IGC 
takes a stand on diverse socio-political cases, and it frequently issues public statements on topics ranging from attacks on journalists to restrictions on freedom of the press to social rights of member journalists.

NGOs studied in this research are generally sensitive about the public profile of their organizations. As stated by its representatives, TGS, unlike the IGC, prefers other methods to gain visibility rather than organizing press conferences or issuing public declarations: "For us, gaining visibility via gaining representative power by having more unionmember journalists is more important, since the unions have lost their power since 1990s and we have to renew our image" (Gökhan Durmuş, personal communication, August 29, 2014). In a similar vein, the IPS Foundation does not define itself as "an action organization". They claim to engage in news and relevant media production activities instead of voicing their opinion on particular issues via press releases, press conferences or similar actions. As stated by the IPS representative, "We are careful about this issue. For instance, we sign public petitions only if it concerns freedom of speech" (Nadire Mater, personal communication, August 30, 2014). ABD, on the other hand, is not only assertive about relevant issues affecting society, but also actively launch campaigns with specific, achievable goals, such as the Phorm campaign (see details in Akin and Ziraman 2015). Similarly, KP has followed a similar role to ABD during the parliamentary debates on the infamous Internet Bill 5651, dramatically increasing its public visibility and influence.

Another practice employed by both types of NGOs in Turkey is engaging in media production in different forms, such as publishing daily newspapers, magazines or running news web-sites. Examples of such productions are "9 Eylül" (9th of September), a regional daily-newspaper published by IGC, "Bizim Gazete" (Our Paper) of Turkish Journalists' Association which recently transferred to online publication, "Foto muhabiri" magazine (Photojournalist) of TFMD (publishing four issues a year), and Bianet of the IPS Foundation. As another form of media production, NGOs publish books or reports relevant to their fields and goals. ABD, INETD, KP, LKD and IPS foundations publish pamphlets, flyers and other informative materials to raise public awareness on particular issues. For instance, $\mathrm{ABD}$ and $\mathrm{KP}$ have published several ebooks on topics such as hacktivism and data protection, and IPS produced 15 books on different aspects of news-production. Similarly, NGO's publish periodical reports about their fields of operation. Several times a year, ABD and INETD report on the status of the Internet, and IPS issues quarterly and annual monitoring reports on violations of freedom of expression (BIA 2016). Another example of media production activities of 
IT-related NGOs is ABD's provision of technical and infrastructure support for Dokuz8, a citizen journalism initiative.

A final practice observed in almost all NGOs studied is that of providing training specific to their field, primarily for members of that NGO. The training programs sometimes take the form of short term public events, such as Linux summer camps co-organized by INETD and LKD, or summer schools organized by the IPS foundation, as well as certificate programs in universities, workshops, public lectures, academic conferences, and other professional training. It is important to highlight these are touted as important platforms that serve the public, and are generally free of charge in order to make the events more accessible. NGOs perceive these events to be valuable recruiting grounds, as stated by the LKD representative: "Even if only ten members of the public participate in our workshop, we are pleased. And if one out of ten of these joins LKD, this makes us very happy" (Destan Sarpkaya, personal communication, September 8, 2014).

\section{Organizational Form and Resources}

Legislation in Turkey allows civil society to organize in several ways: associations (dernek), foundations (vakıf), labor unions (sendika), and cooperatives (kooperatif). Other less structured organizations, such as platforms or collectives, also help bring people together from diverse communities. However, the law in Turkey favors more formal organizations. This is due to the fact that it becomes easier to officially address relevant bodies in case of a possible dispute. For this reason, the $\mathrm{KP}$ preferred to distance itself from the state, and accordingly, they have established a political party initiative. According to Serhat Koç (personal communication, August 29, 2014), "Organizing as an association would put us closer to the state and in our view, the only reason for close relations with the state would be funding. So we have rejected the idea of an association".

NGOs in the field of media are generally formed as associations. According to Kadir Kemaloğlu (personal communication, June 17, 2014), forming as an association instead of a platform brings a higher degree of respectability. Additionally, "associations operating for public interest", a label granted to associations with permission of the Council of Ministers, are eligible for tax exemption and have the right to collect donations without permission. TFMD, for instance, received tax-exempt status in 1984. Since then they have added "Turkish" to their official name, in order to operate at national level and benefit from the privileges accorded to this status. 
According to both Atilla Sertel (personal communication, June 3, 2014), representing the IGC, and Ali Rıza Keleş (personal communication, June 17, 2014) from the ABD, organizing as an association works well, even though, as Keleş stated, the $A B D$ is strikingly different from conventional associations in Turkey. This positive view conflicts with Mustafa Akgül's (personal communication, October 28, 2014) less favorable opinion, which underlines a significant handicap for associations: "The state does not allow associations to make money." To overcome such financial barriers, organizing as a foundation can be helpful. For instance, using the status of "foundation" permits IPS to raise money from international bodies, on the condition that they register the funds as grants.

Another option for the NGOs to organize is by using the labor union structure. It is an effective method that brings the opportunity of executing a collective labor agreement if certain conditions can be fulfilled (such as having a minimum number of members in a workplace). According to Gökhan Durmuş (personal communication, August 29, 2014), "Associations and bodies other than unions do not have the license to improve the economic and personal rights of journalists." Therefore, union membership makes it easier to act. However, it is difficult for unions to enroll members from large-scale commercial media outlets. This complication limits the ambitions of unions in the media in general and for that reason, they generally aim to attract workers at small-scale outlets.

NGOs sustain their activities by utilizing two major forms of sources: their workforce and financial resources. The structural form of an NGO is key in defining how these sources are acquired and managed.

\section{Workforce Sources}

Professional associations enroll members from their relevant fields, while civil society organizations accept members from diverse communities. TFMD, IGC, and TGS draw most members from their particular fields in media industry, whereas anyone can join the ABD, LKD, INETD and KP. Among the current members of the $A B D$, for instance, there are academics, activists and media professionals. Some organizational forms, as in the case of IPS, which is a foundation, do not permit membership; IPS consists of founders and former employees only, and is an exceptional case.

Members of different associations who know each other often cooperate on various efforts, making mobilization easier. The founding members of NGOs have extensive experience in the field, and have developed many contacts within the field, many of which are former colleagues. For instance, as a founding member and the chairman of the 
executive board of the ABD, Ali Rıza Keleş previously worked on Internet censorship within the LKD.

There are many media-related NGOs in Turkey, meaning various options for taking active role in the civil society. This is a good opportunity for the TGS, because they believe that it is easier for them to enroll those already registered with anther NGO. However, the TFMD has concerns about such "divisions within the community". For example, there are four competing journalist associations in Osmaniye, a town with a population of 100.000. According to Kadir Kemaloğlu (personal communication, June $17,2014)$ this leads to "devaluation of the institution." This point of view is also in parallel with the LKD's argument, which emphasizes on disengagement: "There is no connection among the NGOs" (Destan Sarpkaya, personal communication, September 8, 2014).

Civil society organizations seem to be easier to mobilize than the conventional associations, as they are horizontally organized, and used email groups to keep the decision-making processes more streamlined. For instance, LKD has its headquarters in Ankara, however communication is conducted through e-mail groups. Most NGOs also have social media accounts, which are typically used for announcements. ABD opens effectively-run social media accounts, for each event it organizes (such as Kem Gözlere Şiş, Yeni Medya Kongresi).

How the NGOs help mobilize their members depends on their capabilities. Although the professional associations' members outnumber the members-volunteers of the civil society organizations, many of these are inactive. Additionally, some NGOs, such the TGS, take advantage of their legal rights originated from their structural forms. For example, as a union, TGS has the power to enforce labor agreements.

The main issue regarding NGO operations is that volunteers often carry out a bulk of the day-to-day operations. These members, who are already busy with their professional occupations, cannot devote the time and energy necessary for the NGOs' activities. According to Mustafa Akgül (personal communication, October 28, 2014), the deficiencies caused by relying on volunteers is a result of the lack of civil society culture and awareness.

\section{Financial Sources}

Media-related NGOs in Turkey finance their activities in various ways such as membership fees, donations, and income from the NGOs' operations, state-funding, sponsorships, as well as financial support from different institutions, including the international ones.

NGOs in general, mainly depend on membership fees for income, even if these fees represent symbolic amounts. TFMD, for instance, 
collects small amounts from its members; however this constitutes its major source of income. In addition to membership fees, professional associations can access certain of state-funds. Directorate General of Press Advertisement distributes $10 \%$ of profits among the journalists' associations in Turkey, and both IGC and TFMD benefit. Another form of state funding is the revenue from the advertisements in the biannual Bairam newspaper, published by professional journalist associations.

As opposed to the professional associations, who benefit from state funding, civil society organizations have no consistent sources of financial income other than membership fees. NGOs such as ABD and KP occasionally receive donations, but these are not consistent forms of income. Other NGOs, such as the TGS prefer not to accept donations, since this source of income could potentially influence their operations. Under these circumstances, NGOs operating on smaller budgets tend to generate income through the projects they run rather than memberships. These projects are either organized as regular workshops or single events. LKD, ABD, IPS, and TFMD seek for sponsorships on the basis of regular events, such as workshops, competitions, and exhibitions; however, one-time events are also considered. LKD has different categories of sponsorships for the workshops they organize. In some cases, collaboration with other NGOs to develop revenue-generating sponsorships that are needed for survival.

International financial backing is another way of sustaining operations. For instance, IPS has two major donors: European Commission and the Swedish International Development Cooperation Agency (SIDA). Many of their expenditures, including employees' salaries, are covered by the funding from those international organizations.

There are also other sources of income specific to the NGOs. For instance, $A B D$ receives income from the sales of e-books and on a much larger scale, IGC collects rent from its properties that were previously donated to the association.

Many of the NGOs in this study have low operating costs and expenses. In the case of INETD, cost of operations is limited to publishing, conference organizations and transportation. However, the scenario is different for the IPS, as 12 full time employees work for the Bianet, accounting for half of their budget.

\section{Relational Aspects}

In this research, relations of the NGOs are analyzed at two levels: Firstly, relations among the NGOs, including their global connections, and secondly, relations between the state and the civil society. 


\section{Relations among the NGOs}

Media-related NGOs operating in the broadly defined civil society, together with other NGOs, establish relationships over time where they either cooperate of experience conflict (Thompson 1995, 2010). Several factors are observed regarding these relationships.

NGOs that cooperate have relationships that are generally established through individual contacts or on common interests. If the members of an NGO executive board have a good working relationship with representatives of other NGOs, then it is likely for them to develop mutual projects. For instance, as one of the founding members of the Freedom for Journalists Platform (GÖP), and also IGC Executive Board Chairman, Atilla Sertel is the link between GÖP and IGC. A similar scenario applies to the INETD; whose board chairman, Mustafa Akgül, a key figure in establishing the Internet in Turkey, has sustained relations with civic units (including the LKD) through governmental projects.

Types of cooperation also revolve around the fields of their professions. For instance, IGC tries to maintain close relationships with other NGOs, particularly with TGS and Basın-Iş, with the aim of directing their members to those unions. Similarly, TFMD has close relations with other journalism NGOs, such as IGC, Turkey News Cameramen Association (THKD), and Parliament Reporters Association (PMD). TGS also contributes to the mobilization of media workers by closely collaborating with the Turkish Journalists' Association (TGC), Progressive Journalists Association (ÇGD), G9 (a platform for journalists), and IGC. IPS has a broader and varied network, communicating with diverse communities through their own alternative news channels. They collaborate with a wide variety of NGOs, such as the Heinrich Boll Foundation, the Friedrich Ebert Foundation, Kaos GL, TGC, TGS, Rum Vader, Film Mor, the Socialist Feminist Collective, the Hrant Dink Foundation (HDV), and Transparency International. In fact, all NGOs that share common objectives connect with each other and, in certain cases, mutually benefit from their relationships. For instance, IPS offers consulting service to the HDV in return for funding.

Another form of cooperation is observed on a thematic basis. ABD, for instance, collaborates on the issues of censorship and surveillance in order to develop strategies for counter-actions, such as organizing press conferences and lobbying activities in Parliament. These thematic collaborations may also develop into projects; an example is Dokuz8 (a news agency run with support from the citizens) to which ABD provides technical and infrastructural support. Thematic collaborations occasionally bring partnerships for funding applications. The count of these mutual 
applications is relatively high for the IPS; however, many other NGOs prefer to apply individually.

Despite the positive relations between the NGOs, various factors, especially conflict of interests and economic motivations can cause disagreements. Competition is also a source of conflict; for instance, TGS prefers not to work with Medya-İş, which is deemed "loyal to the government", preferring to cooperate with another union, namely Basın-iss. Sometimes competition occurs in a greater scale. TGF, an umbrella body for journalists in Turkey, used to have a number of member organizations. Recently, however, there has been an attempt to create a competing confederation consisting of 40 journalist associations, including the TFMD. Similar situations occur in other professional fields of civil society. As Destan Sarpkaya (personal communication, September 8, 2014) stated, "There are too many NGOs. They all have distinct nuances, and this does not work in practice".

In some cases, NGOs do not collaborate simply because they have different fields of interest. As one of the few NGOs in the field to focus on production, IPS usually collaborates in educational workshops and consultations. KP has distinct approaches to problems, which differ from other NGOs. INETD has its own priorities that typically do not comply with aims of other NGOs. Consequently, NGOs generally favor tactical collaborations with regard to their opportunistic needs and these collaborators are carefully selected. As Ali Rıza Keleş (personal communication, June 17,2014$)$ pointed out: "We don't have relationships with the NGOs that remain close to stakeholders for their own benefits."

In the case of relations among Turkish NGOs and their overseas counterparts, we see positive connections almost all of the time. These global linkages are planned with diverse purposes, including exchange of opinions, networking, mobilization, search for funding, and trainings. Having its foundational roots in Sweden, the KP consistently exchanges information with other Pirate Party initiatives in European countries. They meet with international NGOs such as Access, the Electronic Frontier Foundation (EFF), and European Digital Rights (EDRi). ABD aims to extend its network by joining international civil organizations, such as their recent membership to $\mathrm{EDRi}$, in order to raise awareness about the problems in Turkey and mobilize potential international allies to contend with these issues. IPS maintains close relationships, particularly with funding institutions, like other NGOs. TGS is also an example of an NGO that conducts educational and training opportunities to help with international relationships, as with the Association of European Journalists. These relations accordingly revolve around theme-specific 
occasions. Here, it must be noted that some NGOs are less active at the international level; however, even locally operating NGOs try to allocate time to sustain international relations, as the home political environment forces them to make more collaborations abroad.

\section{Relations with the State}

In Turkey, the relationship between the members of the civil society and the state is highly complex, partly due to the fact that the state apparatus' traditionally strong influence on social life (both as "the ruler" and as "the servant") still has some power to shape the dynamics of today's civil society (Keyman 2006; Zurcher 2004).

The relationship between the state and NGOs is primarily regulated by the judicial system, shaped by the state, whether established in the form of a union (TGS), foundation (IPS) or association (TFMD, IGC, ABD, INETD, LKD). If the NGOs are structured as associations, for instance, they follow the Regulation on Associations: Each association has to register with the Associations Directorate at local level, otherwise they are deemed "illegal" and therefore have no right to operate legally. Accordingly, all associations establish their initial contact with the state, seeking legal approval for their existence. Furthermore, due to various forms of legal authority of the state/government, NGOs develop relations out of necessity, such as IGC requesting permission from the Ministry of Justice to visit journalists in prison.

Apart from the legal and obligatory interactions, all relationships between the NGOs and the state develop via state institutions. ABD, for instance, essentially deals with the Information and Communication Technologies Authority (ICTA). Alternatively, representatives of the NGOs may, at the same time, be members of state-controlled or state-sponsored institutions. Atilla Sertel, the head of IGC, for instance, is a member of the Press Cards Commission and the Directorate General of Press Advertisement, deeming these memberships as his right to opt into governmental regulations. Similarly, TGS, as the union of journalists, has a representative in the same two bodies, and according to the head of TGS, the primary reason for participating in these two state-related platforms is to prevent any form of discrimination that may take place. In other words, both organizations, in order to reserve their right to intervene in any wrongdoing by state institutions, maintain a strong contact with a state board, in order to put forward their critical views.

Some news and IT-related NGOs establish relations with the state institutions with the aim of promoting changes or transformations within their field of operation: For instance, IPS is open to cooperation with the state, especially regarding national action plans driven by partnership 
between the state and NGOs. Likewise, ABD collaborated with the Ministry of National Education for their proposal on a workshop concerning new media literacy and submitted reports to the parliamentary constitution committee regarding the rights of Internet users in Turkey. Similarly in 2012, TFMD, together with THKD and PMD, drafted a code/bylaw about the social rights of journalists and submitted the draft to the deputy prime minister, which eventually led to the improvement of working conditions. In contrast, KP for instance, refrains from any lobbying in Parliament, rejecting any relationship with the state, as a matter of principle.

ABD contacted the Internet Council, affiliated to the ICTA, and was given the opportunity to state their opinions on the current status of the Internet in Turkey. Keleş (personal communication, June 17, 2014) believes that, in the short term, such meetings will have no impact on Internet regulations. Neither INETD nor LKD representatives believe that the state actors seriously consider their expertise and suggestions. As Akgül (personal communication, October 28, 2014) stated, "If what you suggest is not in line with what they want to hear, then you are somehow disregarded." Nevertheless, these meetings can be seen as initial steps for promoting a two-way communication between the NGOs and the state, despite a considerable power imbalance between the two sides of the dialogue.

In some cases, tension arises in the relationship between the NGOs and the state, particularly depending on the socio-political agenda in Turkey. TFMD, for instance, experienced a serious conflict with the state, as the winning entry of the association's annual news photo competition showed the 2013 Gezi Protests. Originally, a state supported bank, Vakıfbank, was the main sponsor of the competition and subsequent exhibitions. Yet after the winner was announced, the bank withdrew sponsorship. For the board member of TFMD, the association was sanctioned simply for doing their job: Choosing a photo as the winner. Here, the member underlines that it's more appropriate to say government, instead of the state since the former takes sides on sociopolitical issues, and the associations' activities do not necessarily align with this perspective.

In a similar vein, TGS experiences "tension" with the state, especially in relation with the issue of freedom of the press. As the Durmuş (personal communication, August 29, 2014) states, this tension peaked when their organization was gaining influence in the state's news agency, namely the Anatolian Agency (AA), and the government reacted by supporting another union (Medya-İş) within $A A$ to counter the representative power, TGS. Yet, neither TFMD nor TGS categorically 
oppose the state. On the contrary, NGOs aim to create positive bonds with the state, mostly by establishing relationships with individual state authorities, to maintain state approval needed to survive in their relevant fields and to continue their operations. Others however, such as the KP, operate entirely independently as they have no expectations of state financial support.

\section{Conclusions}

In this study, NGOs operating in Turkish news and IT fields are examined in order to present their current operations and strategies for improvement or enrichment of their domains, which are increasingly under political and economic pressure. A number of conclusions can be drawn from the study of their goals and actions, organizational forms and sources, as well as relational characteristics.

News and IT-related NGOs, primarily attempt to serve their members' needs and interests to create a positive impact on their relevant fields. This implies that the internal aims of the NGOs, whether directly or indirectly related to their members-volunteers, generally serve as an initial step, or a prerequisite, for the broader societal goals. Whether aiming to empower their professional roles, democratize their fields, or create public pressure on the authorities, NGOs must first unite their members, as well as their volunteers, by prioritizing their interests. NGOs then utilize this resource and organizational structure to address the broader social issues on their agendas.

For many reasons, taking actions to achieve these goals is never straightforward. In the case of professional associations, both the nature of their fields, as well as power structure dominating them, hinder their mobilization. As expressed by the representative of TFMD "being an association-person (dernekçi) in media sector is tricky. On one hand, you deal with heavy workload thanks to the speed of the news flow and try to devote time to your role in the association. On the other hand, when your job security is at the mercy of media bosses, it is not easy to raise your voice" (Kadir Kemaloğlu, personal communication, June 17, 2014). At this point, it is important to emphasize another difference between professional associations and other civil society organizations. Whilst professional associations are subject to direct pressure from the state, as well as from employers, non-governmental civil society organizations have much more freedom. This is because professional organizations are limited the imbalance in power relations with their employers and by their needs to maintain their reputation and to have stronger connections with the state. This difference between professional associations and civil society 
organizations confirms the findings of Fioramonti and Kononykhina (2015) on the diversity of internal dynamics within civil society. This significant theoretical aspect is a key area for future research.

For civil society organizations, mobilization has other complications, such as relying on a loosely connected base of volunteers, lack of sufficient financial resources, and insufficient cooperation with other, sometimes competing, organizations in their respective fields. In order to overcome the latter, namely the lack of cooperation among NGOs, certain organizations, such as the Third Sector Foundation of Turkey (TUSEV), and Civil Society Development Center (STGM), are promoting networking between NGOs to raise awareness of developments in the social sphere. TUSEV, established by Turkey's leading civil society organizations, has now grown to support a network of over 100 associations and foundations that share a vision of strengthening the legal, fiscal and operations infrastructure of the third sector in Turkey. Likewise, STGM aims to help civil organizations improve their work through specific studies and actions designed to fill in their gaps. These two organizations establish communication networks, support efforts to create national platforms and encourage exchange of information and experience among NGOs. Yet despite these efforts, the cooperation among the NGOs is far from the desired level.

It is important to note that the socio-political environment in the Turkey, and various ongoing crises have increased the number of issues faced by these NGOs, as demonstrated in this paper. This further decreases the NGOs' already limited resources available for specific issues. At the same time, it confirms recent warnings in civil society literature about the increasing political and economical constraints they impose (Paker et al. 2013). Yet, the increase of problems in the media field provides the NGOs with an opportunity to address these issues and thus spread their social impact, in so far as resources permit.

Despite these drawbacks, the NGOs in news and IT fields studied in the scope of this research are determined to improve conditions within their respective fields, and such a conclusion is related to the methodological design of this research, namely focusing on news and IT fields separately. An advantage of the field-centered approach deployed in this work is that it enables us to see the field-specific dynamics of individual media affiliates, as well as the condition of each field in terms of the potential for transformation. Such a field-centered approach also reflects the perceptions of those working in these fields, particularly their strong attachments to the field they "defend". As Serhat Koç (personal communication, August 29, 2014) from the KP has asserted, "We are 
representing a party which is specialized in Internet issues. We are defending it in a way an environmentalist defends the environment." Beyond methodological concerns, this "defensive" discourse, which has been internalized by the NGOs studied in this research, implies a reactive rather than a proactive position. In other words, it can be argued that the media-related NGOs investigated have only a limited impact on improving their subdomains, and are restricted simply to protecting them, rather than playing a substantial role in reforming or reshaping Turkey's media landscape.

This brings us to the final conclusion that relates to the choice of NGOs studied in this research and a recommendation for future studies in Turkey's civil society sphere. As stated at the beginning of this paper, the focus of this research was on the NGOs that exist and operate in line with broadly defined democratic principles, and thus, "uncivil" elements were by definition excluded. Yet, as the lengthy discussions on the notion of civil society and NGOs reveal (Diamond 1994; Heinrich 2010; Merkel and Croissant 2004; Shils 1991), there are many other organizations mobilizing in civil society, unconcerned with any form of radical democratic change, but which function as an extension of ongoing power relationships in their relevant fields. Turkey's civil society is not immune to this and there are numerous NGOs in the media field whose actions conflict with democratic principles. Whether mobilizing in line with government party's anti-democratic policies, or via covertly functioning in the interest of established power monopolies, these NGOs have had a significant adverse impact on the conditions of the media field. Indeed, these types of NGOs may have played an influential reforming or reshaping role, which led to the apparent failure of NGOs aligned with democratic principles during the last decades in Turkey. Therefore, future studies should focus on such undemocratic NGOs in order to present "the dark side" of the media-related civil society in Turkey, which is correspondingly as important as the forces portrayed in this paper. Such a line of inquiry could play a role in transforming Turkey's media landscape in accordance with universal democratic norms. 


\section{References}

Akdeniz, Yaman and Kerem Altıparmak (2008), Internet: Restricted access, A Critical Assessment of Internet Content Regulation and Censorship in Turkey, Ankara: Imaj.

Akın, Altuğ and Emrah Zıraman (2015), "Power struggle in/around the Turkish online realm and three forms of opposition: Redhack, Alternative IS Association and personal resistances against YouTube ban", Global Media Journal: Mediterranean Edition, 10 (1), 13-21.

Akın, Altuğ (2016), "Conditions of sense making and news making in Turkey after the failed coup attempt: Sisyphus labor on two fronts", Journalism: Theory, Practice \& Criticism, 18 (4), 518-32.

Aktar, Aktar (2005), Sivil Toplum Kuruluşları Rehberi. İstanbul: Tarih Vakfı Yayınları.

Barış, Ruken (n.d.), Media landscapes: Turkey, European Journalism Centre, (accessed June 5, 2017), [available at http://ejc.net/media landscapes/turkey]

Bianet. (2016), BIA media monitoring reports, (accessed June 5, 2017), [available at http://bianet.org/english/diger/117328-bia-mediamonitoring-reports]

Bikmen, Filiz and Zeynep Meydanoğlu (2006), Civil Society in Turkey and Era of Transition. CIVICUS Civil Society Index: Country Report for Turkey, Third Sector Foundation of Turkey and CIVICUS.

Binark, Mutlu (2012), Türkiye'de Dijital Gözetim: T.C. Kimlik Numarasından E-kimlik Kartlarına Yurttaşın Sayısal Bedenlenişi. Istanbul: Alternatif Bilişim Derneği.

Binark, Mutlu and Koray Löker (2011), Sivil Toplum Örgütleri İçin Bilişim Rehberi. STGM. Ankara.

Cohen, Jean L. and Andrew Arato (1992), Civil Society and Political Theory. Cambridge: MIT Press.

Dağıstanlı, Mustafa A. (2014), 5 ne? 1 Kim?, İstanbul: Postacı Yayınevi.

Dean, Jodi, Jon W. Anderson and Geert Lovink, eds. (2006), Reformatting Politics: Information Technology and Global Civil Society. New York: Routledge.

Dholakia, Nikhilesh and Deniz Atik (2016), "Markets, Globalization, Development: Charting the Intersections of Three Multipolar 
Concepts", Markets, Globalization \& Development Review, 1 (1), 110.

Diamond, Larry J. (1994), "Rethinking Civil Society - Towards Democratic Consolidation", Journal of Democracy, 5, 4-17.

Edwards, Michael (2004), Civil Society. Cambridge: Polity Press.

Engelli Web (n.d.), Erişime engellenen web siteleri, (accessed June 5, 2017), [available at http://engelliweb.com]

Fenton, Natalie (2010), "NGOs, New Media and the Mainstream News: News from Everywhere," in New Media, Old News: Journalism and Democracy in the Digital Age, N. Fenton, ed. London: SAGE.

Fioramonti, Lorenzo and Olga Kononykhina (2015), "Measuring the Enabling Environment of Civil Society: A Global Capability Index", Voluntas, 26, 466-87.

Heinrich, Finn. V (2010), "What makes civil society strong? An innovative approach to conceptualizing, measuring and analysing the strength of civil society in 43 countries," unpublished doctoral dissertation, Faculty of Social Sciences at Freiuniversitat, Hagen.

İçduygu, Ahmet, Zeynep Meydanoğlu and Deniz Ş. Sert (2011), Civil Society in Turkey: At a Turning Point: CIVICUS Civil Society Index (CSI) Project Analytical Country Report for Turkey II, TÜSEV Publications, (accessed June 5, 2017), [available at http://civicus.org/downloads/CSI/Turkey.pdf]

Keane, John (1991), Media and Democracy. Cambridge: Polity Press.

Keyman, Fuat (2006), State Problem in Turkey. Istanbul: Bilgi University Publications.

Kurban, Dilek and Ceren Sözeri (2012), Iktidarın Çarkında Medya: Türkiye'de Medya Bağımsızlığı ve Özgürlüğü Önündeki Siyasi, Yasal ve Ekonomik Engeller. Istanbul: TESEV Yayınları.

Kuzmanovic, Daniella (2010), "Project Culture and Turkish Civil Society", Turkish Studies, 11 (3), 429-44.

Matthew, David and Debora Halbert (2014), The SAGE Handbook of Intellectual Property. London: SAGE.

Merkel, Wolfgang and Aurel Croissant (2004), "Conclusion: Good and Defective Democracies”, Democratization, 11 (5), 199-214. 
Özsever, Atilla (2004), Tekelci Medyada Örgütsüz Gazeteci. İstanbul: İmge Kitabevi.

Paker, Hande, Fikret Adaman, Zeynep Kadirbeyoğlu and Begüm Özkaynak (2013), "Environmental Organisations in Turkey: Engaging the State and Capital", Environmental Politics, 22 (5), 760-78.

Reporters Without Borders (2015), "Press Freedom Index," (accessed June 5, 2017), [available at https://index.rsf.org/\#!/]

Setianto, Benny D. (2007), "Somewhere in between: Conceptualizing civil society", International Journal of Not-for-Profit Law, 10 (1).

Shils, Edward. (1991), "The Virtue of Civil Society", Government \& Opposition, 26 (1), 3-20.

Şimşek, Sefa. (2004), "The Transformation of Civil Society in Turkey: From Quantity to Quality", Turkish Studies, 5 (3), 46-74.

Thompson, John B. (2010), Merchants of Culture: The Publishing Business in the Twenty-First Century. San Francisco: John Wiley \& Sons.

Thompson, John B. (1995), The Media and Modernity: A Social Theory of the Media. Stanford: Stanford University Press.

Tuncel, Hakan (2011), "The media industry in Turkey," IAMCR. (accessed June 5, 2017), [available at https://iamcr.org/medindturkey-2]

TÜIKK (2015), "Yazılı medya istatistikleri, 2012," (accessed June 5, 2017, [available at http://www.tuik.gov.tr/PreHaberBultenleri.do?id=13576]

Twitter (2016), "Transparency Report, July to December 2016," (accessed June 5, 2017), [available at https://transparency.twitter.com/en/informationrequests.htm|\#information-requests-jul-dec-2016]

Wiarda, Howard J. (2003), Civil Society: The American Model and Third World Development. Boulder, CO: Westview Press.

Yeşilada, Birol and Barry Rubin, eds. (2012), Islamization of Turkey under the AKP rule. London: Routledge.

Zurcher, Erik J. (2004), Turkey: A Modern History. London: I. B. Tauris. 